$0 \%$

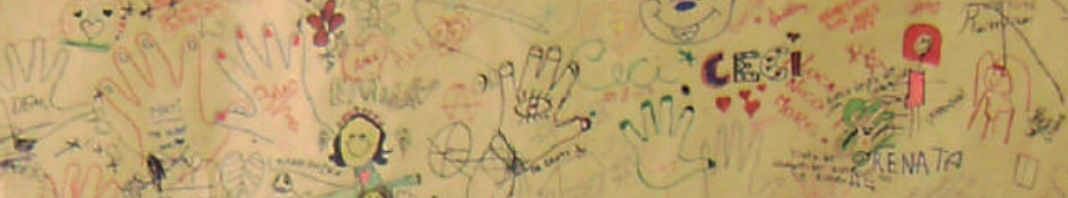
$4 \times n=3$

Rी

$x-12$

and

an:

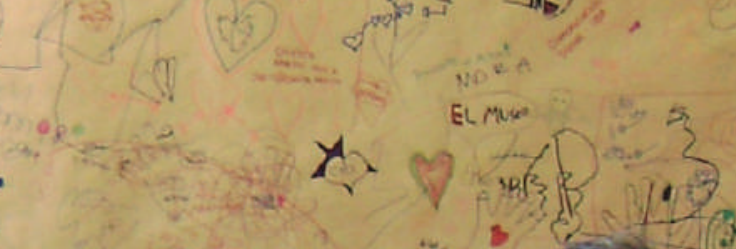

$x=2$.

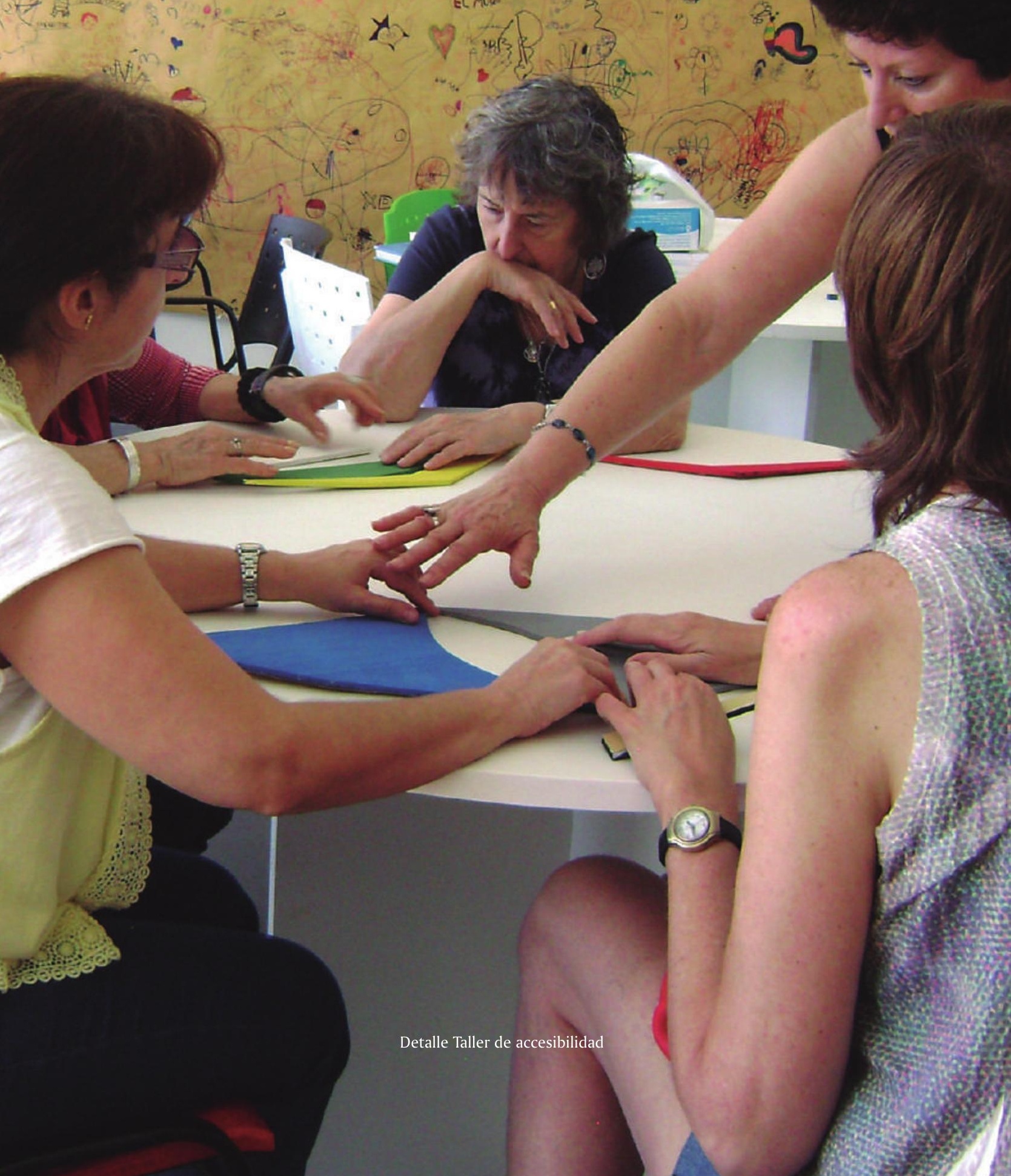




\title{
Participación inclusiva en los museos a favor de las personas con discapacidad
}

\author{
Julio Meza Díaz \\ Western University, Ontario, Canadá \\ jmeza3@uwo.ca
}

\begin{abstract}
Resumen
El presente artículo trata sobre la función social del museo y sus acciones a favor de los derechos igualitarios de las personas con discapacidad, dentro de lo establecido por la Convención Sobre los Derechos de las Personas con Discapacidad (CDPD). Los museos pueden efectivizar los derechos contenidos en el artículo 30 de la CDPD, es decir, el derecho a la accesibilidad a la cultura y a la posibilidad del desarrollo de una agencia artística.
\end{abstract}

Palabras clave: museos, discapacidad, derechos humanos, accesibilidad a la cultura, desarrollo de la agencia en el campo de la cultura.

\begin{abstract}
This paper deals with the social function of the museum and its actions in favor of the equal rights of persons with disabilities, within the provisions of the Convention on the Rights of Persons with Disabilities (CDPD). Museums can make effective the rights contained in article 30 of the CRPD, that is, the right to access to the culture and the right to the possibility to develop an artistic agency.
\end{abstract}

Keywords: museums, disability, human rights, accessibility to culture, development of the agency in the field of culture.

\section{Introducción}

El museo cumple una función social que ha sido resaltada por algunas organizaciones. El Consejo Internacional de Museos (2017) señala en sus estatutos, por ejemplo, que "el museo es una institución permanente, sin fines de lucro, al servicio de la sociedad y de su desarrollo" (p. 3). UNESCO (2015) añade, a su vez, que el museo tiene un rol cohesionador en su comunidad y hace frente a los discursos y prácticas que generan desigualdad.

Bajo el marco de su función social, el museo deja de ser un espacio elitista en donde la centralidad la tienen los objetos que componen las exposiciones (Jung, 2011, p. 321). Se convierte más bien en un espacio comunitario, el cual organiza y dispone de sus recursos en pos de una comunidad mejor, con menos desigualdades, cohesionada, inclusiva y diversa.

El museo puede cumplir su función social a favor de las personas con discapacidad, colaborando con la efectivización de los derechos contenidos en la Convención Sobre los Derechos de las Personas con Discapacidad (CDPD) (ONU, 2006). 
Los derechos de la CDPD que el museo puede efectivizar son los implicados en el artículo 30, es decir, los derechos a la accesibilidad a la cultura y la posibilidad del desarrollo de una agencia ${ }^{1}$ propia en el campo cultural.

El presente artículo, que reúne algunas de las ideas expuestas en la tesis de maestría del autor, $^{2}$ reflexiona sobre el contenido de los derechos mencionados y brinda sugerencias sobre cómo podrían efectivizarse en los museos.

\section{Breve aproximación al marco de derechos humanos de la discapacidad}

La CDPD es el primer documento internacional de la Organización de Naciones Unidas (ONU) en materia de derechos humanos del siglo XXI. La Asamblea General de la ONU la abrió para la firma de sus Estados miembros en 2007.

La CDPD busca centralmente la efectivización de derechos a favor de las personas con discapacidad. Estas personas han sufrido una exclusión histórica, la cual ha tenido como origen los discursos y prácticas elaborados alrededor de la idea de ser humano "normal" (Foucault, 1998, p. 207). Esta idea sobre lo normal ha justificado tanto la segregación social como la conculcación de derechos de aquellos considerados "anormales".

La CDPD define la discapacidad del siguiente modo:

Es un concepto que evoluciona y que resulta de la interacción entre las personas con deficiencias y las barreras debidas a la actitud y al entorno que evitan su participación plena y efectiva en la sociedad, en igualdad de condiciones con las demás (ONU, 2006, p. 1). La discapacidad está constituida entonces por dos elementos interrelacionados. El primero se refiere a las limitaciones de las personas, las cuales pueden ser físicas, sensoriales, psicosociales o cognitivas. El segundo implica la exclusión social que se da a partir de dichas limitaciones. Un ejemplo puede graficar mejor la definición de discapacidad.

Pensemos en una persona sorda que se interrelaciona comunicativamente con los demás mediante la lengua de señas de su país. Si esta persona quiere denunciar en alguna comisaría haber sido víctima de un delito y no encuentra a ningún policía que conozca el lenguaje de señas, no podrá ejercer su derecho de acceso a la justicia. Si, por el contrario, la misma persona es atendida por policías instruidos en el lenguaje de señas, habrá ejercido plenamente sus derechos como el resto de ciudadanos. La discapacidad es resultado entonces de una sociedad "discapacitante" (Berman, 2007, p. 2).

Para superar las barreras sociales, la CDPD obliga a los Estados partes (es decir, a los Estados que han firmado y ratificado el documento internacional), a reconocer la capacidad jurídica de las personas con discapacidad (ONU, 2006, p. 11). Esto significa que los Estados reconocen que las personas con discapacidad pueden ejercer los mismos derechos que los demás. Entre estos derechos están, por ejemplo, los relacionados con el campo económico, la vida sexual y reproductiva, y la participación política.

La CDPD obliga también a los Estados partes a convenir en el propósito de "promover, proteger y asegurar el goce pleno y en condiciones de igualdad de todos los derechos humanos y libertades fundamentales por todas las personas con discapacidad" (ONU, 2006, p. 1).

1 Por agencia entendemos a la capacidad de los individuos para actuar de forma intencional o buscando un propósito.

2 La tesis titulada Participación inclusiva en museos a favor de las personas con discapacidad. Un análisis del planeamiento estratégico en los museos de arte de la Ciudad de Buenos Aires, fue sustentada en junio del presente año. 


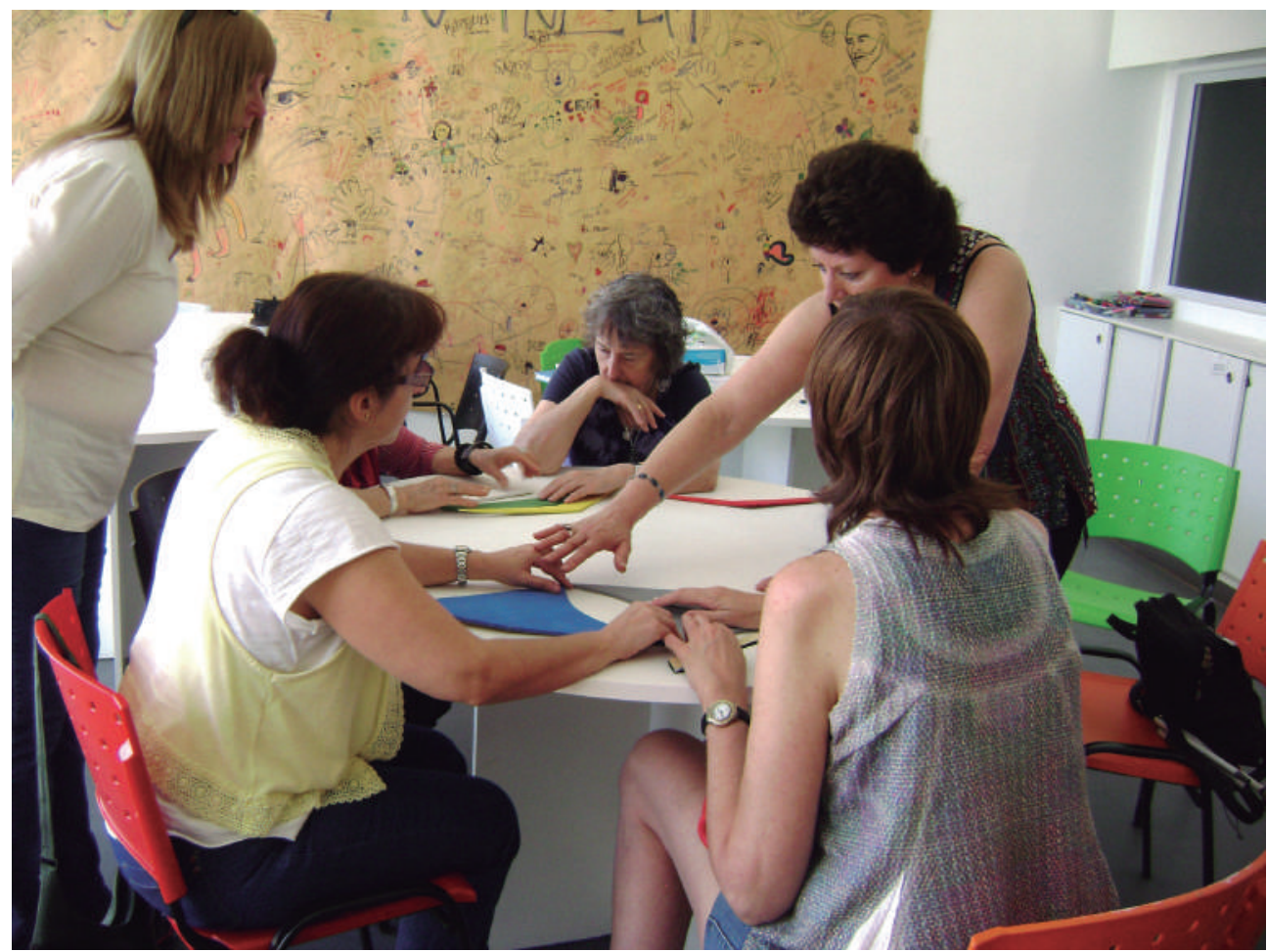

Taller de accesibilidad con materiales táctiles, dirigido por Mabel Mayol, para comprender mejor las obras expuestas en sala. Museo Nacional de Bellas Artes de Buenos Aires, 2016. Foto: Julio Meza Díaz

La CDPD quiere entonces cambiar las condiciones sociales de las personas con discapacidad. Para este propósito, hace que los Estados partes reconozcan los derechos de dichas personas y luchen contra su exclusión, a la vez que favorece su resguardo y la efectivización de sus derechos.

La CDPD ha sido firmada y ratificada por todos los países de la región sudamericana. En la Argentina, ${ }^{3}$ Chile ${ }^{4}$ y el Perú, ${ }^{5}$ por ejemplo, tiene rango constitucional, es decir, forma parte de los derechos fundamentales ${ }^{6}$ de cada uno de los países mencionados. En consecuencia, estos tienen el deber de modificar las normas, prácticas y discursos del Estado y el sector privado que contravengan a la CDPD. ${ }^{7}$

Ahora bien, es pertinente recordar que los derechos humanos son marcos normativos y su mera existencia no es suficiente para que se concreticen. Aunque en teoría son de obligatorio cumplimiento, se necesita de luchas sociales para que realmente se vuelvan efectivos (Quiroga, 2010, pp. 6-16). La CDPD es un marco normativo internacional y depende de

3 Ver: Ley N. ${ }^{\circ} 27.044$ del Congreso de la Argentina, 2014.

4 Ver: Decreto N. ${ }^{\circ}$ 201, del Ministerio de Relaciones Exteriores de Chile, 2008.

5 Ver: Resolución Legislativa N. ${ }^{\circ} 29127$ del Congreso de la República del Perú, 2007.

6 Entendemos como derechos fundamentales a los derechos humanos reconocidos en un ordenamiento jurídico nacional.

7 Si acaso la CDPD tuviera rango de ley, modificaría las leyes previas sobre la materia, y las prácticas y discursos del sector estatal y privado. 


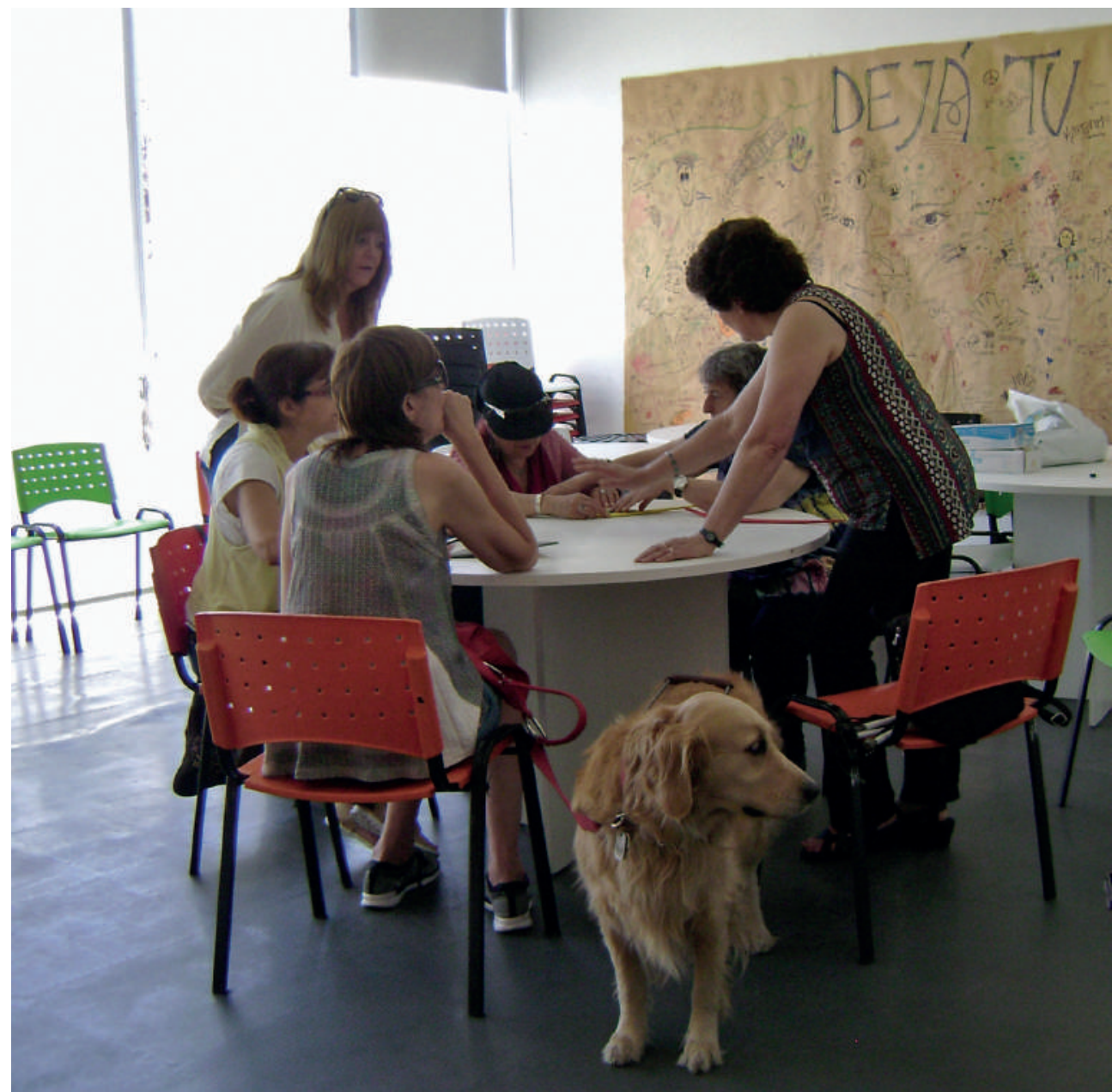

Taller de accesibilidad. Museo de Nacional de Bellas Artes de Buenos Aires, 2016.

Detalle: Perro guía para persona con ceguera. Foto: Julio Meza Díaz

cada Estado y de la sociedad civil para lograr su aplicación en amplia o reducida medida. Esta aplicación pasa por el proceso de la firma y ratificación de la CDPD, la modificación de todas las normas que la contravienen y, sobre todo, la transformación de los discursos y prácticas sociales que conforman las barreras sociales y que perennizan la exclusión.

Estos esfuerzos se realizan entonces desde diversos espacios (el de las organizaciones civiles, el del poder legislativo, el de la investigación y la cátedra, y el de la divulgación a través de los medios de comunicación, por ejemplo). En esta labor a favor de la efectivización de la CDPD, el museo, tanto de administración estatal como privada, cumple con su función social dando sus propios aportes. Estos implican a los derechos contenidos en la participación inclusiva.

\section{Participación inclusiva en los museos}

Para efectos del presente artículo, seguimos lo postulado por el Convenio Andrés Bello (2015), el cual define cultura como "aquellas actividades humanas y sus manifestaciones, cuya razón de ser consiste en la creación, producción, difusión, transmisión, consumo y 
apropiación de contenidos simbólicos” (p. 42). Esta definición se compone de actividades, prácticas e industrias que implican "patrimonio cultural y natural; patrimonio cultural inmaterial; presentaciones artísticas y celebraciones; artes visuales y artesanías; libros y prensa; medios audiovisuales e interactivos; diseño y servicios creativos" (López, 2012, p. 7).

Siguiendo la definición citada, leemos el artículo 30 de la CDPD, el que señala:

1. Los Estados Partes reconocen el derecho de las personas con discapacidad a participar, en igualdad de condiciones con las demás, en la vida cultural y adoptarán todas las medidas pertinentes para asegurar que las personas con discapacidad: a) Tengan acceso a material cultural en formatos accesibles; b) Tengan acceso a programas de televisión, películas, teatro y otras actividades culturales en formatos accesibles; c) Tengan acceso a lugares en donde se ofrezcan representaciones o servicios culturales tales como teatros, museos, cines, bibliotecas y servicios turísticos y, en la medida de lo posible, tengan acceso a monumentos y lugares de importancia cultural nacional.

2. Los Estados Partes adoptarán las medidas pertinentes para que las personas con discapacidad puedan desarrollar y utilizar su potencial creativo, artístico e intelectual, no sólo en su propio beneficio sino también para el enriquecimiento de la sociedad (ONU, 2006, p. 25).

La CDPD reconoce la participación en la cultura de las personas con discapacidad y la entiende constituida de dos derechos. El primero es la accesibilidad a los bienes y servicios culturales (consumo). ${ }^{8}$ El segundo es la actuación o agencia dentro del campo cultural (producción). El museo puede efectivizar ambos derechos humanos.

\subsection{Accesibilidad a la cultura}

En la actualidad, existe abundante bibliografía especializada sobre el derecho humano a la accesibilidad a la cultura. Estos textos incluyen descripciones y reflexiones sobre las diversas acciones a favor de la accesibilidad implementadas en los museos (Espinosa y Bonmatí, 2015, pp. 13-20).

De acuerdo con Madariaga y Rubio (2013), la accesibilidad en los museos puede ser física, comunicativa y social (pp. 812 y 813 ).

Las acciones a favor de la accesibilidad física deben focalizarse en la eliminación de los obstáculos y buscar que las personas con discapacidad (en especial, las que tienen discapacidad física o visual) puedan entrar, salir y utilizar la infraestructura y equipamientos (Cátedra de ocio y discapacidad, 2014, p. 10). Se tiene que hacer uso, entonces, de elementos arquitectónicos, como por ejemplo, la colocación de rampas y ascensores.

Estas acciones no pueden detenerse bajo la excusa de la intangibilidad de los edificios históricos en los que funcionan algunos museos. De acuerdo con el Comité Sobre los Derechos de las Personas con Discapacidad (CODPD) (2014), ${ }^{9}$ los Estados partes están obligados a hacer accesibles dichos sitios. Las transformaciones a favor de la accesibilidad física, por lo demás, nunca comprometen la integridad de los edificios. Se pueden realizar preservando la identidad de los edificios y sin perjudicar su valor histórico (p. 14).

8 De acuerdo con el Comité Sobre los Derechos de las Personas con Discapacidad (2014), la accesibilidad en general es "una condición previa esencial para que las personas con discapacidad disfruten [y ejerzan] de manera efectiva y en condiciones de igualdad de los derechos civiles, políticos, económicos, sociales y culturales" (p. 2). Es entonces un derecho que posibilita el ejercicio de otros derechos.

9 El Comité está constituido por un conjunto de expertos independientes que supervisa la aplicación de la CDPD en cada Estado parte. Las observaciones que publica el comité constituyen doctrina jurídica que se emplea para la interpretación de la CDPD. Empleamos las siglas CODPD para el Comité. De este modo, las diferenciamos de las siglas que utilizamos para la convención, CDPD. 
Las acciones a favor de la accesibilidad comunicativa tratan sobre la señalización e información en términos cualitativos y cuantitativos (Madariaga y Rubio, 2013, p. 812). En los museos se deben implementar acciones que impliquen la señalización táctil o sonora, lo que posibilita que las personas con discapacidad (centralmente, aquellas con discapacidad visual) se ubiquen y desenvuelvan en todo el espacio. Se tienen que ofrecer además itinerarios táctiles y/o sonoros que permitan una visita informada y autónoma de la totalidad de la muestra (Ministerio de Sanidad, Política Social e Igualdad, y Ministerio de Cultura de España, 2011, p. 30).

Las acciones a favor de la accesibilidad social se centran en la educación de los trabajadores de los museos al respecto de la CDPD. Estas acciones se tienen que focalizar en aquellos que tratan con el público, así como en los que diseñan los programas de actividades y las estrategias de marketing y contenidos publicitarios. Los trabajadores de los museos que tratan con el público deben haber superado los estereotipos vinculados con la discapacidad (en especial, con las discapacidades cognitiva y psicosocial, las cuales generan mayor exclusión) y tienen que cumplir un rol de apoyo, es decir, deben ayudar a las personas con discapacidad a concretizar sus decisiones (Cátedra de ocio y discapacidad, 2014, pp. 10 y 11).

Los responsables de diseñar los programas de actividades deben estar educados en la CDPD para que dichos programas colaboren con la visibilización de la problemática de la discapacidad y generen actitudes positivas hacia la diversidad, lo que incluye abordar temas de otros colectivos como la comunidad LGBTIQ y los inmigrantes (Cátedra de ocio y discapacidad, 2014, pp. 4 y 5). Finalmente, los diseñadores de los contenidos publicitarios y estrategias de marketing tienen que hacer productos accesibles, además de referir y celebrar la diversidad (Madariaga y Rubio, 2013, p. 812 y 813).

Las acciones a favor de la accesibilidad social incluyen también la comunicación con las asociaciones de personas con discapacidad, con el propósito de organizar visitas guiadas para los miembros de dichas asociaciones en las instalaciones de los museos (Ministerio de Sanidad, Política Social e Igualdad, y Ministerio de Cultura de España, 2011, p. 30).

El modo en que hemos expuesto la organización de las acciones, es decir, divididas en físicas, comunicativas y sociales, es solo una opción de sistematización. Otra forma de organizar las acciones a favor de la accesibilidad en los museos puede darse dividiéndolas de acuerdo al público al que están dirigidas. Así se ha hecho en la Argentina, en donde las acciones se clasifican según se dirijan a las personas con discapacidad física, auditiva, visual o psicosocial (Ministerio de Turismo de la Nación, 2010).

Por otra parte, la lista de acciones enumeradas no pretende agotar las posibilidades físicas, comunicativas y sociales a favor de la accesibilidad a la cultura en los museos. La búsqueda de dicha accesibilidad habría que contemplarla como una actividad creativa, la cual se basa sobre el ideal del diseño universal. Este consiste en que las personas con y sin discapacidad tendrían que poder usar los mismos equipamientos y recursos, disfrutando de la misma posibilidad de consumo cultural (Madariaga, 2009, p. 19).

\subsection{Desarrollo de una agencia en el campo cultural}

El derecho humano a la posibilidad del desarrollo de una agencia en el campo cultural no ha sido, al parecer, lo suficientemente estudiado.

De acuerdo con Morris (2008), la subjetividad de las personas con discapacidad casi no ha tenido presencia en el campo cultural, porque las personas sin discapacidad han definido la representación cultural de las personas con discapacidad. Así, la falta de discapacidad se ha representado como lo deseable, positivo y universal, mientras que la discapacidad se 


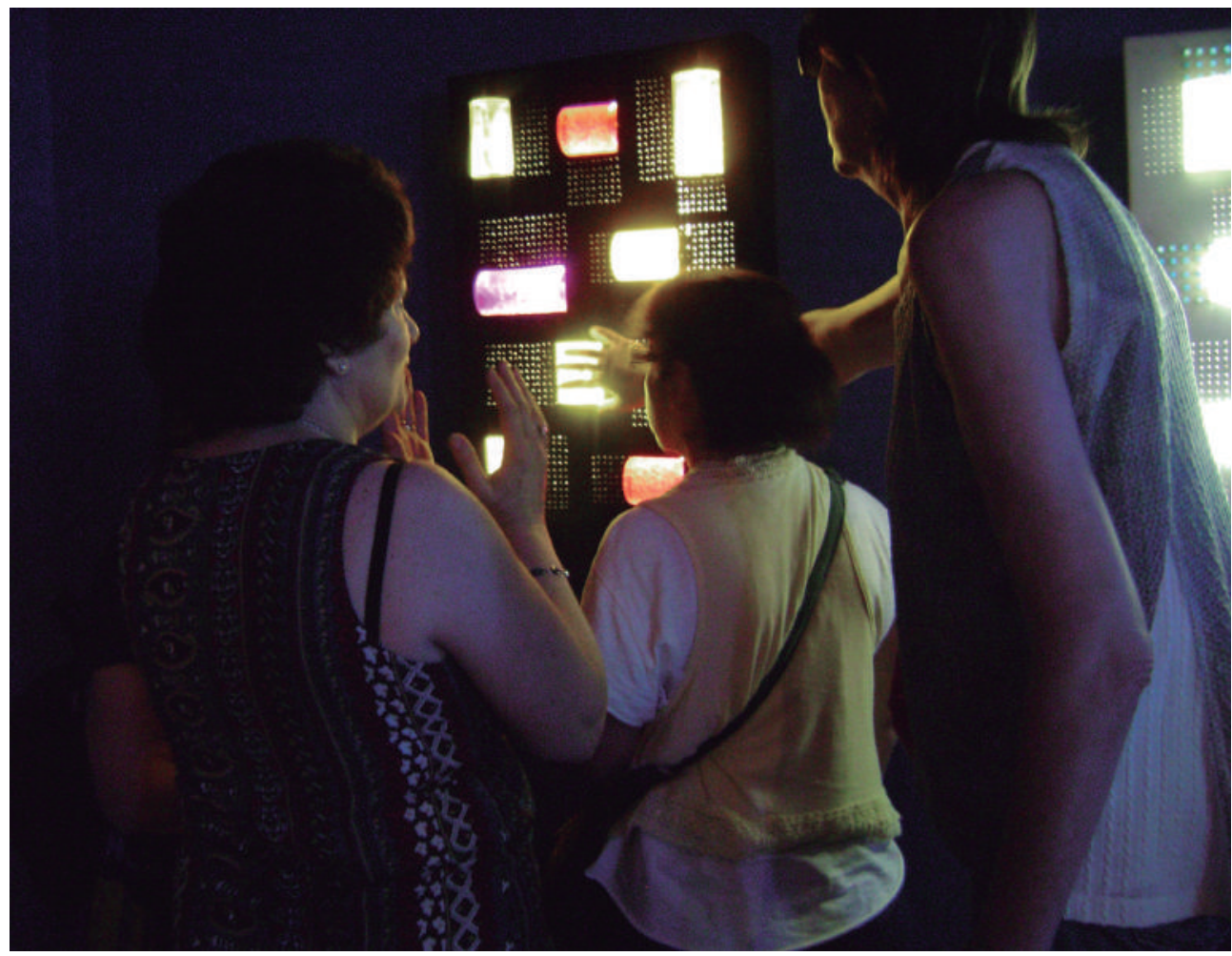

Experiencia táctil para personas con discapacidad visual. Se emplea una obra de arte expuesta en sala. Museo Nacional de Bellas Artes de Buenos Aires, 2016. Foto: Julio Meza Díaz

ha representado como una experiencia negativa y restringida. Se ha establecido, entonces, una representación opresiva de la discapacidad. Para romper con ella, las personas con discapacidad tienen que apropiarse de cómo se les ha venido definiendo, y traducir y dar a conocer sus realidades subjetivas (pp. 316-321). Consideramos que este propósito podría lograrse efectivizando el derecho al desarrollo de una agencia en el campo cultural.

Este derecho puede concretizarse en todos los museos, aunque quizás los museos de arte sean los espacios más adecuados para el tratamiento del tema. Las acciones a favor del derecho pueden incluir el fomento de la creación artística mediante talleres accesibles, premios a la creación artística y la realización de exposiciones (de personas con discapacidad y de estas en conjunto con otras sin discapacidad) (Ministerio de Sanidad, Política Social e Igualdad, y Ministerio de Cultura de España, 2011, p. 34). Estas acciones se tienen que trabajar en coordinación con los centros educativos dedicados al arte.

El Museo de Arte Moderno de Sao Paulo (2018), mediante su programa Igual diferente, brinda un ejemplo de acciones a favor del derecho al desarrollo de la agencia artística. Este programa ofrece cursos gratuitos y es accesible a todos los públicos, "independientemente de sus condiciones físicas, sociales o psíquicas”. Entre los cursos del tercer cuatrimestre de 2018 están Corposinalizante y Escultura. El primero se ofrece a personas con discapacidad auditiva y oyentes, y se centra en el arte vinculado a la lengua de signos brasilera. El segundo tiene como estudiantes a personas con ceguera, baja visión y videntes, y se aboca a la reflexión sobre las imágenes y su producción. 


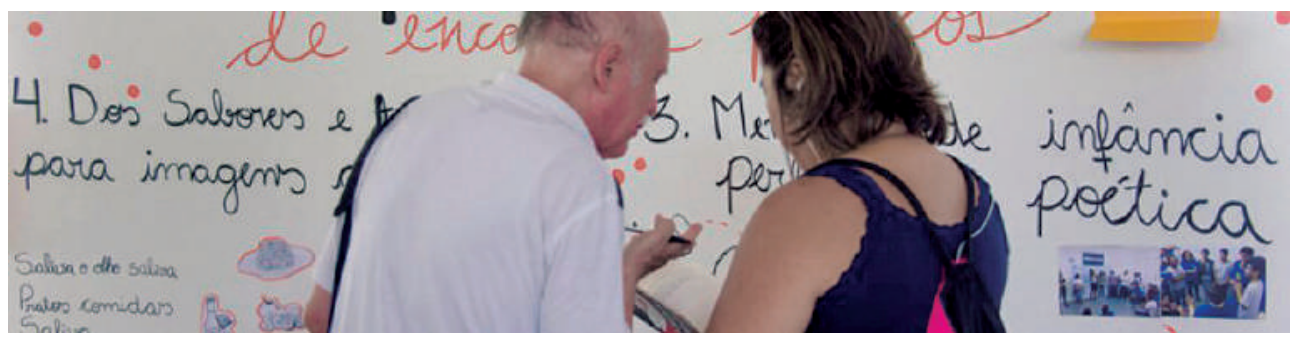

Imagen de Igual-Diferente, programa ofrecido para personas sin y con discapacidad auditiva. Busca la reflexión y el desarrollo del arte vinculado a la lengua de signos brasilera. Fuente: web del Museo de Arte Moderno de Sao Paolo

\section{Conclusiones}

La función social del museo interrelaciona a esta institución con su comunidad. El museo deja de ser un espacio elitista, en donde los objetos son lo central, y se convierte en un centro comunitario, que responde a las necesidades sociales, en un marco inclusivo, de respeto y promoción de la diversidad, así como de lucha a favor de la reducción de las desigualdades.

La CDPD es un documento internacional de la ONU sobre derechos humanos. Su propósito central es la efectivización de derechos igualitarios a favor de las personas con discapacidad, las cuales constituyen un grupo humano que ha sido históricamente excluido.

La CDPD ha sido firmada y ratificada por todos los países de la región latinoamericana. En algunos ha ingresado al sistema jurídico nacional con rango constitucional. El sector estatal y el privado están obligados a cambiar las normas que contravengan la CDPD y sus discursos y prácticas que producen exclusión. Sin embargo, más allá de dicha obligación, en la práctica se requiere del esfuerzo de diversos actores sociales para la efectivización de la CDPD.

Cumpliendo con su función social, el museo puede colaborar con la efectivización de los derechos contenidos en el artículo 30 de la CDPD, los cuales implican la accesibilidad a la cultura y la posibilidad del desarrollo de una agencia artística.

El primer derecho permite el consumo cultural de las personas con discapacidad en igualdad de condiciones que las demás. Este derecho debe implementarse teniendo en cuenta la accesibilidad física, comunicativa y social, y partiendo del ideal del diseño universal. El segundo derecho sirve como herramienta para acabar con la representación opresiva de la discapacidad. Tiene que implementarse con acciones que fomenten la creación y otorguen el reconocimiento, respetando la subjetividad y las identidades grupales de las personas con discapacidad. 


\section{Referencias bibliográficas}

Cátedra de Ocio y Discapacidad (2014). Manifiesto por un ocio inclusivo. Alcalá: Cermi, Fundación Once, Once.

Comité Sobre los Derechos de las Persona-s con Discapacidad (2014). Observación general N. ${ }^{\circ} 2$. Artículo 9: Accesibilidad. 16 pp. Ginebra: ONU.

Consejo Internacional de Museos (2017). Estatutos. 13 pp. ICOM: París. Recuperado de https://icom.museum/wp-content/ uploads/2018/07/2017_ICOM_Statutes_SP_01. pdf. [Visto el 13-08-2018]].

Convenio Andrés Bello (2015). Guía metodológica para la implementación de las Cuentas Satélite de Cultura en Iberoamérica. 261 pp. Bogotá: CAB.

Berman, R. (2007). Desarrollo Inclusivo: un aporte universal desde la discapacidad. Equipo de Discapacidad y Desarrollo Inclusivo. Región de Latinomérica y el Caribe: Banco Mundial. Recuperado de http://ecaths1.s3.amazonaws.com/ orghosp/901049776.DESARROLLOINCLUSIVO. doc. [Visto 10-08-2018].

Espinosa, A; Bonmatí, C. (2015). Accesibilidad, inclusión y diseño para todas las personas en museos y patrimonio. Her \& Mus.Heritage and Museography, 16, 7(1) 1120. Guijón: Ediciones Trea.

Foucault, M. (1998). Historia de la locura en la época clásica, tomo 1. México D.F.: Fondo de Cultura Económica. Jung, Y. (2011). The art museum ecosystem: a new alternative model. En Museum management and curatorship, 26(4), 321-338.

López, O. (2012). Reflexiones para abordar estadísticas sobre las relaciones entre cultura y desarrollo a partir de los avances de la batería de indicadores C+D UNESCO. En I. Gálvez (Coord). Seminario cultura y desarrollo: aplicación de indicadores, 4-42. Ciudad de México: Conaculta.
Madariaga, A. (Mayo, 2009). Ocio y discapacidad: el reto de la inclusión. En Edinamia: ocio y tecnología. 22 pp. Simposio llevado a cabo en Elche, Alicante.

Madariaga, A; Rubio F. (2013). La inclusión en ocio de las personas con discapacidad: una línea de trabajo en el marco de la política social. En Actas del IV Congreso de la red española de política social: las políticas sociales entre crisis y postcrisis, 806-819. Alcalá: Universidad de Alcalá.

Ministerio de Turismo de la Nación (2010). Directrices de accesibilidad en servicios turísticos. 295 pp.; CABA: Ministerio de Turismo de la Nación.

Morris, J. (2008). Lo personal y lo político. Una perspectiva feminista sobre la investigación de la discapacidad física. En L. Barton (Coord.). Superar las barreras de la discapacidad, pp. 315-326. Madrid: Ediciones Morata.

Organización de Naciones Unidas (2006). Convención sobre los derechos de las personas con discapacidad. Ginebra: ONU.

Quiroga, M. (2010). Derechos humanos: ¿derechos naturales? En Brújula. Revista de ideas de la asociación de egresados y graduados de la Pontificia Universidad Católica del Perú, (19) 6-16. Lima: Pontificia Universidad Católica del Perú, Asociación de egresados y graduados.

UNESCO (2015). Recomendación relativa a la protección y promoción de los museos y colecciones, su diversidad y su función en la sociedad. UNESCO: París. Recuperado de http://portal.unesco.org/es/ev.phpURL $\mathrm{ID}=49357 \& \mathrm{URL}$ DO $=$ DO_TOPIC\&URL_SEC$\mathrm{TION}=201 . \mathrm{html}$. [Visto 13-8-2018].

Recibido el 20 de julio del 2018. Aceptado el 28 de agosto del 2018. 